\title{
Sex Differences in Diagnosis and Clinical Phenotypes of Chinese Children with Autism Spectrum Disorder
}

\author{
Shihuan Wang ${ }^{1} \cdot$ Hongzhu Deng ${ }^{1} \cdot$ Cong You ${ }^{1} \cdot K^{K a i y u n}$ Chen $^{1} \cdot$ Jianying $\mathrm{Li}^{1} \cdot$ \\ Chun Tang ${ }^{1} \cdot$ Chaoqun Ceng $^{1} \cdot$ Yuanyuan Zou ${ }^{1} \cdot$ Xiaobing Zou $^{1}$
}

Received: 9 October 2016/Accepted: 22 January 2017/Published online: 25 February 2017

(c) The Author(s) 2017. This article is published with open access at Springerlink.com

\begin{abstract}
The aim of this study was to explore the differences between boys and girls in the diagnosis and clinical phenotypes of autism spectrum disorder (ASD) in China's mainland. Children diagnosed with ASD ( $n=1064,228$ females) were retrospectively included in the analysis. All children were assessed using the Autism Diagnostic Interview-Revised (ADI-R) and Autism Diagnostic Observation Schedule (ADOS). The results showed that girls scored significantly higher in ADI-R socioemotional reciprocity than boys, and also scored lower in ADI-R and ADOS restricted and repetitive behaviors (RRBs). Meanwhile, the proportions of girls who satisfied the diagnostic cut-off scores in the ADI-R RRBs domain were lower than in boys $(P<0.05)$. Our results indicated that girls with ASD show greater socio-emotional reciprocity than boys. Girls also tended to show fewer RRBs than boys, and the type of RRBs in girls differ from those in boys. The ADI-R was found to be less sensitive in girls, particularly for assessment in the RRBs domain.
\end{abstract}

Keywords Autism spectrum disorder - Sex differences . Diagnosis

Hongzhu Deng

denghongzhu@foxmail.com

Xiaobing Zou

zouxb@163.net

1 Child Developmental and Behavioral Center, Third Affiliated Hospital of Sun Yat-sen University, Guangzhou 510630, China

\section{Introduction}

Autism spectrum disorder (ASD) is a set of heterogeneous neurodevelopmental disorders characterized by developmental delays in social communication and restricted and repetitive behaviors (RRBs) [1]. Based on the most recent epidemiological surveys, the global prevalence of ASD is estimated to be $1 \%-2 \%[2,3]$. Males are disproportionately represented at $\sim 4: 1[4,5]$. While epidemiological studies have confirmed the male dominance in ASD, the reason for this is unclear. The original description, diagnostic criteria, and clinical data for ASD were based almost solely on males, with relatively few studies focusing on females. Several studies have reported that females with ASD might exhibit behaviors, cognitive functioning, neuroanatomy, and gene expression patterns different from males [6-8]. However, the characterization of ASD in females is far from complete.

Few studies have explored sex differences within the core clinical phenotypes in children with ASD, and the results are inconsistent. Some studies have reported greater stereotypical play and RRBs in males with ASD. Bölte et al. found that males exhibit more RRBs than females in adult high-functioning autism as assessed using the Autism Diagnostic Observation Schedule (ADOS) [9]. Hattier et al. also reported a higher frequency of RRBs in adult males regardless of age range as assessed using the Stereotypies subscale of the Diagnostic Assessment for the Severely Handicapped-II [10]. However, some investigators have found no such sex differences in the RRBs domain $[11,12]$. In the social communication domain, Frazier et al. recently reported that females with ASD (age range, 4-18 years) have greater social communication impairment than males [13]. Hiller et al. reported that girls with ASD are more likely to integrate non-verbal and 
verbal behaviors, maintain reciprocal conversation, and be able to initiate friendships [14]. In contrast, other studies have found no sex differences in early social-communication skills [15]. Collectively, these studies suggest potential differences in the symptoms of ASD between males and females. However, a clear and consistent picture of the clinical phenotypes of ASD in females has not yet emerged. This may be due to variability in the age of patients, sample sizes, diagnostic criteria, and assessment tools used in previous studies.

Females have been reported to be more likely to experience a lack of diagnosis, delay in diagnosis, and misdiagnosis. Goin-Kochel et al. reported that girls were diagnosed later for Asperger's disorder (average $8.9 \mathrm{vs}$. 7.0 years) and pervasive developmental disorder-not otherwise specified (average 5.1 vs. 3.9 years), when compared with boys [16]. Koenig and Tsatsanis highlighted that sex differences at the time of presentation have not been sufficiently addressed in validation studies of the key diagnostic instruments, such as the ADI-R and ADOS [17]. There is a paucity of research addressing the validity of diagnostic criteria, particularly in females. In addition, symptom criteria or assessment items may be biased, raising doubts about the criteria and content validity of the ADI-R and ADOS diagnostic algorithms, especially in relation to females.

Few studies have been conducted on sex differences in core clinical phenotypes in children with ASD, specifically in Asian populations. Early abnormal developmental differences between boys and girls with ASD remain unknown. The primary objective of the present study was to explore sex differences in the domains of social communication and RRBs in children with ASD in a large sample from an Asian community. The second objective was to retrospectively analyze the differences in early abnormal development between boys and girls with ASD based on the ADI-R. A third objective was to further explore the differences in diagnostic cut-off scores for ADI-R and ADOS between boys and girls with ASD.

\section{Methods}

\section{Participants}

The sample retrospectively included 1064 individuals (228 girls and 836 boys). These children were diagnosed with ASD in a single-center clinic-The Child Developmental $\&$ Behavioral Center in the Third Affiliated Hospital of Sun Yat-sen University, Guangzhou-between June 2013 and October 2015. The participants selected were 24-83 months old. Inclusion criteria: children who fulfilled the ASD diagnostic criteria based on the Diagnostic and
Statistical Manual of Mental Disorders, 4th Edition, Text Revision (DSM-IV-TR) [18]. Exclusion criteria: children with mental retardation, idiopathic language retardation, or schizophrenia. There were no gender differences in the exclusion samples (11 girls and 47 boys).

\section{Diagnostic Assessment}

\section{The Autism Diagnostic Interview-Revised (ADI-R)}

The ADI-R [19] is a semi-structured parent/caregiver interview designed to assess and quantify the developmental history of autism-specific behaviors. It contains 93 items, including development of early childhood, language development, communication functioning, social reciprocity, play, and RRBs. The ADI-R diagnostic items constitute 4 domains: social reciprocity (A: cut-off $\geq 10$ ), communication (B: cut-off $\geq 8$ for verbal and $\geq 7$ for nonverbal individuals), RRBs (C: cut-off $\geq 3$ ), and abnormal development before 36 months ( $D$ : cut-off $\geq 1$ ). Verbal children were defined as those who have spontaneous, echoed, or stereotyped language, which on a daily basis, involves phrases of three words or more [19]. The cut-off scores were defined as satisfying the autism diagnostic criteria. The social reciprocity domain (A) consists of nonverbal behaviors to regulate social interaction (A1), developing peer relationships (A2), sharing enjoyment (A3), and socio-emotional reciprocity (A4). The communication domain (B) consists of gesture communication (B1), conversation (B2, only for verbal individuals), repetitive speech (B3, only for verbal individuals), and play (B4). The RRBs domain (C) consists of unusual preoccupation, circumscribed interest, verbal rituals, compulsions/ rituals, hand and finger mannerisms, stereotyped body movements, repetitive use of objects/interest in parts of objects, and unusual sensory interest. Abnormal development before 36 months (D) consists of age when parents first noticed developmental abnormalities, age when developmental abnormalities probably first manifested in interviewer's judgment, age of first single words, and age of first phrases. In the ADI-R items, word speech delay is defined as the age at first single words $>24$ months, and phrase speech delay is defined as the age at first phrase $>33$ months.

\section{The Autism Diagnostic Observation Schedule (ADOS)}

The ADOS is a standardized assessment tool for children with suspected ASD [20]. It involves a semi-structured interview with interspersed activities and tasks intended to elicit behaviors associated with ASD. It covers communication, social reciprocity, play/imagination, and RRBs. Depending on the child's language level, verbal children 
received module 2 assessment, while non-verbal children received module 1 assessment. The cut-off scores for satisfying the autism diagnostic criteria were defined in the domains of social reciprocity (A) and communication (B). For module 1 , the cut-off for autism was $\mathrm{A}+\mathrm{B} \geq 12$, with $\mathrm{A} \geq 7$ and $\mathrm{B} \geq 4$. For module 2 , the cut-off for autism was $\mathrm{A}+\mathrm{B} \geq 12$, with $\mathrm{A} \geq 6$ and $\mathrm{B} \geq 5$.

\section{Statistical Analyses}

Data were analyzed using the Statistical Package for Social Sciences (version 20.0; SPSS Inc., Chicago, IL). The differences in baseline characteristics between boys and girls with ASD were examined using $\chi^{2}$-test. The scores in the social communication domain were normally distributed, while the scores for different types of RRBs were skewed. Sex differences in the scores for the social communication domain and early abnormal development were tested using Analysis of Covariance, with sex as the fixed factor and age as the covariate. The differences in the scores for different types of RRBs between boys and girls with ASD were determined using Mann-Whitney $U$ tests. The differences in cut-off scores with respect to social reciprocity, communication, and RRBs between boys and girls with ASD were examined using $\chi^{2}$-test. $P<0.05$ was considered statistically significant. Effect Size (ES) was used to estimate the sex effect.

\section{Results}

\section{Demographic Characteristics}

The baseline demographic characteristics are listed in Table 1 . There were no statistically significant age differences between boys and girls for both verbal and non- verbal children. Word and phrase speech delay was more frequently reported in girls than in boys $\left(\chi^{2}=21.82,7.67\right.$; $P<0.05 ; \mathrm{ES}=0.14,0.09)$. While most children were diagnosed with autism, only $7.46 \%$ of girls and $7.66 \%$ of boys were diagnosed with Asperger's disorder. There were no sex differences in the distribution of diagnoses.

\section{Sex Differences in Social Reciprocity and Communication Domains}

No significant between-group differences were found in total social reciprocity scores based on ADI-R and ADOS in verbal and non-verbal children (Table 2). However, detailed analysis of social reciprocity revealed that verbal and non-verbal girls with ASD scored higher in terms of ADI-R socio-emotional reciprocity than boys $(P=0.049$, 0.001; $\mathrm{ES}=0.22,0.38$ ).

No sex-based differences were found in total verbal communication scores based on ADI-R and ADOS in verbal children (Table 3). However, verbal girls with ASD scored higher in ADI-R gesture communication than boys $(P<0.001 ; \quad \mathrm{ES}=0.40)$, and non-verbal girls scored higher in the ADOS communication domain than boys $(P=0.006 ; \mathrm{ES}=0.32)$. In addition, verbal girls scored lower in ADI-R repetitive speech than boys $(P=0.003$; $\mathrm{ES}=0.29$ ).

\section{Sex Differences in RRBs Domain}

Girls with ASD $(3.59 \pm 1.87)$ scored lower than boys $(4.55 \pm 2.06)$ in total RRBs based on the ADI-R $(F=39.03, P<0.001 ; \mathrm{ES}=0.32)$, and girls with ASD $(2.02 \pm 1.47)$ also scored lower in RRBs than boys $(2.30 \pm 1.41)$ based on the ADOS $(F=7.73, P=0.006$; $\mathrm{ES}=0.13)$. Based on the ADI-R, non-verbal girls with
Table 1 Baseline demographic characteristics of children with ASD.

\begin{tabular}{lllllc}
\hline & $\begin{array}{l}\text { Girls with ASD } \\
\text { Mean (SD) }\end{array}$ & $\begin{array}{l}\text { Boys with ASD } \\
\text { Mean (SD) }\end{array}$ & Effect size & $\mathrm{t} / \chi^{2}$ & $P$ \\
\hline$n$ & 228 & 836 & 0.03 & 0.84 & 0.361 \\
Verbal (\%) & $134(58.77 \%)$ & $463(55.38 \%)$ & & & \\
Non-verbal (\%) & $94(41.23 \%)$ & $373(44.62 \%)$ & & & \\
Age in months & & & & & \\
Verbal & $52.04(17.86)$ & $55.07(16.32)$ & 0.18 & 0.85 & 0.065 \\
Non-verbal & $35.49(10.79)$ & $36.37(10.84)$ & 0.06 & 0.71 & 0.48 \\
Word speech delay $(n, \%)$ & $155(67.98)$ & $423(50.60)$ & 0.14 & 21.82 & $<0.001$ \\
Phrase speech delay $(n, \%)$ & $103(45.18)$ & $294(35.17)$ & 0.09 & 7.67 & 0.006 \\
Diagnosis $(n, \%)$ & & & & 0.51 & 0.474 \\
Autism & $204(89.47)$ & $761(91.03)$ & 0.06 & 0.01 & 0.92 \\
Asperger's disorder & $17(7.46)$ & $64(7.66)$ & 0.01 & 3.32 & 0.069 \\
PDD-NOS & $7(3.07)$ & $11(1.31)$ & 0.18 & \\
\hline
\end{tabular}

ASD, autism spectrum disorder; PDD-NOS, pervasive developmental disorder-not otherwise specified; SD, standard deviation. 
Table 2 Descriptive statistics for social reciprocity domain in girls and boys with ASD.
Table 3 Descriptive statistics for the communication domain in girls and boys with ASD.

\begin{tabular}{|c|c|c|c|c|c|}
\hline Scores & $\begin{array}{l}\text { Girls with ASD } \\
\text { Mean (SD) }\end{array}$ & $\begin{array}{l}\text { Boys with ASD } \\
\text { Mean (SD) }\end{array}$ & Effect size & $F$ & $P$ \\
\hline \multicolumn{6}{|c|}{ Non-verbal behaviors to regulate social interaction (A1) } \\
\hline Verbal & $3.20(1.22)$ & $3.04(1.18)$ & 0.13 & 1.69 & 0.194 \\
\hline Non-verbal & $3.69(1.25)$ & $3.56(1.30)$ & 0.10 & 0.86 & 0.353 \\
\hline \multicolumn{6}{|c|}{ Develop peer relationships (A2) } \\
\hline Verbal & $4.13(1.85)$ & $4.13(1.90)$ & 0.00 & 1.17 & 0.279 \\
\hline Non-verbal & $3.20(1.60)$ & $3.17(1.55)$ & 0.02 & 0.33 & 0.568 \\
\hline \multicolumn{6}{|c|}{ Share enjoyment (A3) } \\
\hline Verbal & $3.77(1.48)$ & $3.62(1.52)$ & 0.10 & 0.46 & 0.499 \\
\hline Non-verbal & $4.59(1.27)$ & $4.60(1.35)$ & 0.01 & 0.01 & 0.907 \\
\hline \multicolumn{6}{|c|}{ Socio-emotional reciprocity (A4) } \\
\hline Verbal & $4.99(1.98)$ & $4.62(1.60)$ & 0.22 & 3.89 & 0.049 \\
\hline Non-verbal & $6.35(1.84)$ & $5.70(1.65)$ & 0.38 & 11.08 & 0.001 \\
\hline \multicolumn{6}{|c|}{$A D I-R$ social reciprocity domain $(A)$} \\
\hline Verbal & $16.10(4.83)$ & $15.41(4.02)$ & 0.16 & 3.30 & 0.070 \\
\hline Non-verbal & $17.83(4.57)$ & $17.03(4.21)$ & 0.19 & 3.12 & 0.078 \\
\hline \multicolumn{6}{|c|}{ ADOS social reciprocity domain $(A)$} \\
\hline Verbal & $8.93(2.74)$ & $8.80(2.80)$ & 0.04 & 0.13 & 0.715 \\
\hline Non-verbal & $9.86(2.33)$ & $9.42(2.68)$ & 0.17 & 1.97 & 0.161 \\
\hline
\end{tabular}

ADI-R Social reciprocity domain $\mathrm{A}=\mathrm{A} 1+\mathrm{A} 2+\mathrm{A} 3+\mathrm{A} 4$.

ASD, autism spectrum disorder; SD, standard deviation.

\begin{tabular}{|c|c|c|c|c|c|}
\hline Scores & $\begin{array}{l}\text { Girls with ASD } \\
\text { Mean (SD) }\end{array}$ & $\begin{array}{l}\text { Boys with ASD } \\
\text { Mean (SD) }\end{array}$ & Effect size & $F$ & $P$ \\
\hline \multicolumn{6}{|c|}{ Gesture communication (B1) } \\
\hline Verbal & $4.12(2.06)$ & $3.27(2.07)$ & 0.40 & 14.54 & $<0.001$ \\
\hline Non-verbal & $5.78(1.71)$ & $5.62(1.92)$ & 0.08 & 0.52 & 0.473 \\
\hline \multicolumn{6}{|c|}{ Conversation (B2) } \\
\hline Verbal & $2.69(1.38)$ & $2.90(1.44)$ & 0.14 & 1.70 & 0.192 \\
\hline \multicolumn{6}{|c|}{ Repetitive speech (B3) } \\
\hline Verbal & $2.78(1.01)$ & $3.10(1.16)$ & 0.29 & 9.04 & 0.003 \\
\hline \multicolumn{6}{|l|}{ Play (B4) } \\
\hline Verbal & $3.87(1.31)$ & $4.03(1.33)$ & 0.12 & 1.42 & 0.233 \\
\hline Non-verbal & $4.99(1.07)$ & $4.97(1.01)$ & 0.02 & 0.04 & 0.85 \\
\hline \multicolumn{6}{|c|}{ ADI-R communication domain $(B)$} \\
\hline Verbal & $13.46(3.44)$ & $13.30(3.63)$ & 0.05 & 0.05 & 0.824 \\
\hline Non-verbal & $10.77(2.36)$ & $10.59(2.50)$ & 0.07 & 0.39 & 0.533 \\
\hline \multicolumn{6}{|c|}{ ADOS communication domain $(B)$} \\
\hline Verbal & $5.87(1.88)$ & $5.50(2.07)$ & 0.18 & 2.32 & 0.128 \\
\hline Non-verbal & $6.56(1.58)$ & $5.99(1.85)$ & 0.32 & 7.65 & 0.006 \\
\hline
\end{tabular}

ADI-R communication domain: $\mathrm{B}($ verbal $)=\mathrm{B} 1+\mathrm{B} 2+\mathrm{B} 3+\mathrm{B} 4 ; \mathrm{B}($ non-verbal $)=\mathrm{B} 1+\mathrm{B} 4$.

ASD, autism spectrum disorder; SD, standard deviation.
ASD scored higher than boys in hand and finger mannerisms and stereotyped body movements $(Z=2.13,2.22$; $P=0.033,0.026)$. Conversely, non-verbal boys with ASD scored higher than girls in unusual preoccupation, repetitive use of objects, and interest in parts of objects
( $Z=2.15,7.95$; all $P<0.05)$. In addition, verbal boys with ASD scored higher than girls in unusual preoccupation, circumscribed interest, verbal rituals, repetitive use of objects, and interest in parts of objects $(Z=2.83,2.54$, 2.98, 9.22; all $P<0.05$ ) (Table 4). 


\section{Sex Differences in Early Abnormal Development}

Based on the ADI-R, the age when parents first noticed developmental abnormalities in both verbal and non-verbal girls was later than in boys $(F=34.06,51.09$; all $P<0.001 ; \mathrm{ES}=0.45,0.54)$. Meanwhile, the age when developmental abnormalities probably first manifested in the interviewer's judgment in both verbal and non-verbal girls was also later than in boys $(F=114.27,115.56$; $P<0.001 ; \mathrm{ES}=0.44,0.56$ ). Furthermore, the age at which single words and phrases were first spoken by verbal girls was higher than that of boys $(F=6.94,8.16$; $P=0.009,0.004 ; \mathrm{ES}=0.25,0.26$ ) (Table 5).

\section{Sex Differences in Diagnostic Cut-off Scores}

The differences in diagnostic cut-off scores in boys and girls with ASD are summarized in Table 6. A lower proportion of verbal girls with ASD satisfied the cut-off scores for ASD relative to boys $(89.85 \%)$ in the ADI-R repetitive stereotyped behaviors domain $\left(\chi^{2}=20.53, P<0.001\right.$,
$\mathrm{ES}=0.19)$. A lower proportion of non-verbal girls (73.40\%) satisfied the cut-off scores for ASD relative to boys $(84.72 \%)$ in the same domain $\left(\chi^{2}=6.64, P=0.010\right.$, $\mathrm{ES}=0.12$ ).

\section{Discussion}

\section{Sex Differences in Core Clinical Phenotypes in Children with ASD}

An important finding emerging from our study is the strong suggestion that both verbal and non-verbal girls with ASD have greater socio-emotional reciprocity impairment than boys, while non-verbal girls show more serious communication impairment than boys. Socio-emotional reciprocity includes use of the body to communicate, offering comfort, quality of expression of social interest, appropriate facial expressions, and appropriateness of social response. Holtmann et al. examined sex differences using the ADI-R and ADOS for participants with high-

Table 4 Descriptive statistics for repetitive stereotyped behaviors domain in girls and boys with ASD.

\begin{tabular}{|c|c|c|c|c|c|c|c|c|}
\hline \multirow[t]{2}{*}{ Scores } & \multicolumn{3}{|c|}{ Girls $(n=228)$} & \multicolumn{3}{|c|}{ Boys $(n=836)$} & \multirow[t]{2}{*}{$Z$} & \multirow[t]{2}{*}{$P$} \\
\hline & 0 & 1 & 2 & 0 & 1 & 2 & & \\
\hline \multicolumn{9}{|c|}{ Unusual preoccupation } \\
\hline Verbal & $90(39.47 \%)$ & $33(14.47 \%)$ & $11(4.82 \%)$ & $252(30.14 \%)$ & $137(16.39 \%)$ & $74(8.85 \%)$ & 2.83 & 0.005 \\
\hline Non-verbal & $60(26.32 \%)$ & $28(12.28 \%)$ & $6(2.63 \%)$ & $200(23.92 \%)$ & $116(13.88 \%)$ & $57(6.82 \%)$ & 2.15 & 0.032 \\
\hline \multicolumn{9}{|c|}{ Circumscribed interest } \\
\hline Verbal & $68(29.82 \%)$ & $54(23.68 \%)$ & $12(5.26 \%)$ & $201(24.04 \%)$ & $158(18.90 \%)$ & $104(12.44 \%)$ & 2.54 & 0.011 \\
\hline Non-verbal & $64(28.07 \%)$ & $25(10.96 \%)$ & $5(2.19 \%)$ & $285(34.09 \%)$ & $62(7.42 \%)$ & $26(3.11 \%)$ & 1.45 & 0.141 \\
\hline \multicolumn{9}{|c|}{ Verbal rituals* } \\
\hline Verbal & $91(39.91 \%)$ & $37(16.23 \%)$ & $6(2.63 \%)$ & $261(31.22 \%)$ & $126(15.07 \%)$ & $76(9.09 \%)$ & 2.98 & 0.003 \\
\hline \multicolumn{9}{|c|}{ Compulsions/rituals } \\
\hline Verbal & $58(25.44 \%)$ & $55(24.12 \%)$ & $21(9.21 \%)$ & $257(30.74 \%)$ & $110(13.16 \%)$ & $96(11.48 \%)$ & 1.45 & 0.148 \\
\hline Non-verbal & $54(23.68 \%)$ & $31(13.60 \%)$ & $9(3.95 \%)$ & $247(29.55 \%)$ & $69(8.25 \%)$ & $57(6.82 \%)$ & 0.97 & 0.331 \\
\hline \multicolumn{9}{|c|}{ Hand and finger mannerisms } \\
\hline Verbal & $87(38.16 \%)$ & $36(15.79 \%)$ & $11(4.82 \%)$ & $325(38.88 \%)$ & $83(9.93 \%)$ & $55(6.58 \%)$ & 0.77 & 0.442 \\
\hline Non-verbal & $51(22.37 \%)$ & $28(12.28 \%)$ & $15(6.58 \%)$ & $248(29.67 \%)$ & $80(9.57 \%)$ & $45(5.38 \%)$ & 2.13 & 0.033 \\
\hline \multicolumn{9}{|c|}{ Stereotyped body movements } \\
\hline Verbal & $81(35.53 \%)$ & $39(17.11 \%)$ & $14(6.14 \%)$ & $256(30.62 \%)$ & $114(13.64 \%)$ & $93(11.12 \%)$ & 1.67 & 0.096 \\
\hline Non-verbal & $34(14.91 \%)$ & $40(17.54 \%)$ & $20(8.77 \%)$ & $201(24.04 \%)$ & $92(11.00 \%)$ & $81(9.69 \%)$ & 2.22 & 0.026 \\
\hline \multicolumn{9}{|c|}{ Repetitive use of objects/interest in parts of objects } \\
\hline Verbal & $72(31.58 \%)$ & $50(21.93 \%)$ & $12(5.26 \%)$ & $73(8.73 \%)$ & $206(24.64 \%)$ & $184(22.01 \%)$ & 9.22 & $<0.001$ \\
\hline Non-verbal & $37(16.23 \%)$ & $43(18.86 \%)$ & $14(6.14 \%)$ & $33(3.95 \%)$ & $145(17.34 \%)$ & $195(23.33 \%)$ & 7.95 & $<0.001$ \\
\hline \multicolumn{9}{|c|}{ Unusual sensory interest } \\
\hline Verbal & $58(25.44 \%)$ & $67(29.39 \%)$ & $9(3.95 \%)$ & $213(25.48 \%)$ & $254(30.38 \%)$ & $26(3.11 \%)$ & 0.45 & 0.881 \\
\hline Non-verbal & $26(14.40 \%)$ & $48(21.05 \%)$ & $20(8.77 \%)$ & $114(13.64 \%)$ & $219(26.20 \%)$ & $40(4.78 \%)$ & 1.68 & 0.093 \\
\hline
\end{tabular}

$* P<0.05$; all comparisons between boys and girls with ASD (autism spectrum disorder).

Scores for different types of RRBs are ranked data; differences in skewed scores between boys and girls with ASD compared using MannWhitney U tests. 
Table 5 Comparison of early abnormal development in girls and boys with ASD.

\begin{tabular}{|c|c|c|c|c|c|}
\hline Age (months) & $\begin{array}{l}\text { Girls with ASD } \\
\text { Mean (SD) }\end{array}$ & $\begin{array}{l}\text { Boys with ASD } \\
\text { Mean (SD) }\end{array}$ & Effect size & $F$ & $P$ \\
\hline \multicolumn{6}{|c|}{ Age when parents first noticed developmental abnormalities } \\
\hline Verbal & $34.71(12.80)$ & $29.73(10.61)$ & 0.45 & 34.06 & $<0.001$ \\
\hline Non-verbal & $27.27(11.03)$ & $21.94(6.69)$ & 0.54 & 51.09 & $<0.001$ \\
\hline \multicolumn{6}{|c|}{ Age when developmental abnormalities probably first manifest in interviewer's judgment } \\
\hline Verbal & $32.21(9.72)$ & $24.50(7.32)$ & 0.44 & 114.27 & $<0.001$ \\
\hline Non-verbal & $27.45(8.88)$ & $20.26(5.85)$ & 0.56 & 115.56 & $<0.001$ \\
\hline \multicolumn{6}{|c|}{ Age of first single words } \\
\hline Verbal & $23.81(8.11)$ & $21.79(7.85)$ & 0.25 & 6.94 & 0.009 \\
\hline \multicolumn{6}{|c|}{ Age of first phrases } \\
\hline Verbal & $31.25(9.51)$ & $28.98(8.29)$ & 0.26 & 8.16 & 0.004 \\
\hline
\end{tabular}

ASD, autism spectrum disorder; SD, standard deviation. functioning autism matched for age (range, 5-20 years), and found that females have greater impairment in playing with the peer group and social problems as per the reports of parents based on ADI-R [21]. A recent study by Howe et al. revealed that verbal girls with ASD show greater impairment of social communication than males, based on the ADOS [22]. A possible explanation for this could be related to lower cognitive function in girls with ASD. Previous studies have suggested that girls with ASD have lower cognitive ability than boys [23]; Frazier also pointed out that females with a lower IQ have greater communication impairment [13]. The results of the present study suggest that girls with ASD exhibit a clinical phenotype different from that in boys.

To date, very few studies have documented differences in RRBs between girls and boys. In the present study, we found that girls with ASD showed fewer RRBs than boys, using both the ADI-R and ADOS. We also found that girls with ASD exhibited more stereotyped body movements (e.g. repetitive circling and jumping up and down) and hand and finger mannerisms (mechanical play with the hand) than boys, while boys exhibited more unusual preoccupations (e.g. with metal objects, lights, and traffic signs), verbal rituals (e.g. questioning knowingly and forcing others to speak), repetitive use of objects, and interest in parts of objects (e.g. playing with wheels and turning the lights on and off). In addition, boys with ASD exhibited more repetitive speech than girls. These results suggest that girls with ASD show different types of RRBs than boys, and that girls more commonly develop special repetitive stereotyped behaviors.

Girls with ASD are more likely to mask atypical interest, and this would not be considered an RRB in girls. For example, parents may report that their daughter likes to play with dolls. However, when probed about exactly how she 'played', it could become apparent that every session involved repeated brushing of hair, with little flexibility or imagination. This condition can be misinterpreted as an imaginative game for girls, rather than as an RRB [24]. Moreover, some special characteristics of RRBs in girls were absent from the diagnostic algorithms. For example, ASD girls often carry the same books when going outside, which may also be considered an RRB, but this is not included among the diagnostic criteria in the ADI-R [25]. In addition, some activities in boys are more likely to be considered RRBs. For example, parents may report that their son likes to play with trains or dinosaurs. While this may be considered a "special interest", on further inquiry it may be a little stronger without affecting other interests [26]. Consequently, clinicians should carefully look for RRBs in ASD children to identify those common to both boys and girls. The notion that girls show fewer RRBs may be a "protective" factor for girls that in turn makes a formal diagnosis of ASD more difficult. Szatmari et al. suggested that this "protective" mechanism may have an underlying genetic component, consistent with the genethreshold model for girls with ASD [27]. This model assumes that the threshold for ASD in females is higher than in males [28]. In other words, females require a greater genetic load to manifest autistic behaviors. As a result, once females are formally diagnosed, their cognitive function and behavioral characteristics tend to be more severe than in males.

\section{Sex Differences in Identification and Diagnosis in Children with ASD}

Our results revealed that the age when parents first noticed developmental abnormalities and the age when developmental abnormalities probably first manifested in the interviewer's judgment in girls were later than in boys. Furthermore, the age at which single words/phrases were first spoken was also later in girls than in boys. Collectively, the results suggest that early abnormal development 
Table 6 Descriptive statistics for cut-off scores in girls and boys with ASD.

\begin{tabular}{|c|c|c|c|c|c|}
\hline & $\begin{array}{l}\text { Girls with ASD } \\
\text { Satisfied cut-off scores }(n)\end{array}$ & $\begin{array}{l}\text { Boys with ASD } \\
\text { Satisfied cut-off scores }(n)\end{array}$ & Effect size & $\chi^{2}$ & $P$ \\
\hline \multicolumn{6}{|c|}{$A D I-R$ social reciprocity (A) } \\
\hline Verbal & $123(91.79 \%)$ & $447(96.54 \%)$ & 0.10 & 5.44 & 0.020 \\
\hline Non-verbal & $88(93.62 \%)$ & $361(96.78 \%)$ & 0.07 & 2.03 & 0.154 \\
\hline \multicolumn{6}{|c|}{ ADI-R communication $(B)$} \\
\hline Verbal & $127(94.78 \%)$ & $450(97.19 \%)$ & 0.06 & 1.87 & 0.171 \\
\hline Non-verbal & $91(96.81 \%)$ & $351(94.10 \%)$ & 0.05 & 1.09 & 0.297 \\
\hline \multicolumn{6}{|c|}{$A D I-R$ RRBS $(C)$} \\
\hline Verbal & $100(74.63 \%)$ & $416(89.85 \%)$ & 0.19 & 20.53 & $<0.001$ \\
\hline Non-verbal & $69(73.40 \%)$ & $316(84.72 \%)$ & 0.12 & 6.64 & 0.010 \\
\hline \multicolumn{6}{|c|}{ ADI-R abnormal development before 36 months $(D)$} \\
\hline Verbal & $130(97.01 \%)$ & $458(98.92 \%)$ & 0.06 & 2.54 & 0.111 \\
\hline Non-verbal & $93(98.93 \%)$ & $370(99.20 \%)$ & 0.01 & 0.06 & 0.807 \\
\hline \multicolumn{6}{|c|}{ ADOS communication $(B)$} \\
\hline Verbal & $128(95.52 \%)$ & $426(92.01 \%)$ & 0.06 & 1.92 & 0.166 \\
\hline Non-verbal & $93(98.94 \%)$ & $370(99.20 \%)$ & 0.01 & 0.06 & 0.807 \\
\hline \multicolumn{6}{|c|}{ ADOS social reciprocity $(A)$} \\
\hline Verbal & $131(97.76 \%)$ & $452(97.62 \%)$ & 0.00 & 0.01 & 0.926 \\
\hline Non-verbal & $94(100.00 \%)$ & $366(98.12 \%)$ & 0.06 & 1.79 & 0.181 \\
\hline \multicolumn{6}{|c|}{ ADOS communication + social reciprocity $(A+B)$} \\
\hline Verbal & $130(97.01 \%)$ & $432(93.30 \%)$ & 0.07 & 2.59 & 0.107 \\
\hline Non-verbal & $94(100.00 \%)$ & $364(97.59 \%)$ & 0.07 & 2.31 & 0.128 \\
\hline
\end{tabular}

and behavioral characteristics for girls are not as easy to identify and are liable to be missed by both parents and evaluators. This may lead to delayed diagnosis of ASD in girls. Shattuck et al. reported that the age at which the diagnosis of ASD is made in girls is significantly later than in boys (average 6.1 vs. 5.6 years) [29]. Previous studies have reported no obvious sex differences in core symptoms after controlling for age and IQ. However, girls with ASD tend to show more emotional problems, attention deficit, and thought problems [14]. This suggests that girls are diagnosed only when they exhibit more behavioral problems. One possible explanation for this difference is that boys are comparatively more likely to exhibit hyperactivity and repetitive use of objects, and exhibit interest in parts of objects to trigger detection and identification by parents or clinicians. In contrast, the characteristic behaviors in ASD girls are not always as overt and thus are liable to be missed. Clinical symptoms in high-functioning autistic girls (e.g. those exhibiting fewer RRBs) are particularly prone to be missed or misdiagnosed.

We also revealed that the proportion of both verbal and non-verbal girls who satisfied the cut-off scores in the RRBs domain was lower than in boys when assessed using the ADI-R. The ADI-R may be less sensitive for diagnosing ASD in girls, particularly in the RRBs domain. Girls with ASD may be under-identified due to RRBs not satisfying the cut-off scores for diagnosis. Wilson et al. noted that sex affects the diagnosis and evaluation of ASD, suggesting that females and males demonstrate distinct clinical phenotypes [26]. As such, sex differences need to be incorporated into the current diagnostic tools. This viewpoint has been articulated by several clinicians. There is therefore a call for tailoring the current diagnostic and assessment tools to address sex differences, in order to improve the diagnostic rate of ASD in girls.

\section{Conclusions}

Our findings suggest that girls with ASD show greater socio-emotional reciprocity, and non-verbal girls suffer more communication impairment than boys. Girls tend to show fewer RRBs than boys, and the types of RRBs for girls may be different from those for boys. Early abnormal development and behavioral characteristics in girls are not easy to recognize. In addition, the ADI-R is less sensitive for girls, particularly assessment in the RRBs domain. Clarifying sex differences in diagnosis and clinical phenotype will assist in answering the question of why fewer girls are diagnosed with ASD than boys, and may provide clinical guidance for early screening, diagnosis, and intervention. 
Acknowledgements This work was supported by the National Natural Science Foundation of China (81471017) and a Scientific Project of the Ministry of Health of China (201302002).

Open Access This article is distributed under the terms of the Creative Commons Attribution 4.0 International License (http://crea tivecommons.org/licenses/by/4.0/), which permits unrestricted use, distribution, and reproduction in any medium, provided you give appropriate credit to the original author(s) and the source, provide a link to the Creative Commons license, and indicate if changes were made.

\section{References}

1. Lai MC, Lombardo MV, Baron-Cohen S. Autism. Lancet 2014, 383: 896-910.

2. Elsabbagh M, Divan G, Koh YJ, Kim YS, Kauchali S, Marcín C, et al. Global prevalence of autism and other pervasive developmental disorders. Autism Res 2012, 5: 160-179.

3. Kim YS, Leventhal BL, Koh YJ, Fombonne E, Laska E, Lim EC, et al. Prevalence of autism spectrum disorders in a total population sample. Am J Psychiatry 2011, 168: 904-912.

4. Blumberg SJ, Bramlett MD, Kogan MD, Schieve LA, Jones JR, $\mathrm{Lu}$ MC. Changes in prevalence of parent-reported autism spectrum disorder in school-aged U.S. children: 2007 to 2011-2012. Natl Health Stat Report 2013, 20: 1-11.

5. Fombonne E. Epidemiology of autistic disorder and other pervasive developmental disorders. J Clin Psychiatry 2005, 66 Suppl 10: 3-8.

6. Beacher FD, Minati L, Baron-Cohen S, Lombardo MV, Lai MC, Gray MA, et al. Autism attenuates sex differences in brain structure: a combined voxel-based morphometry and diffusion tensor imaging study. AJNR Am J Neuroradiol 2012, 33: 83-89.

7. Lai MC, Lombardo MV, Suckling J, Ruigrok AN, Chakrabarti B, Ecker C, et al. Biological sex affects the neurobiology of autism. Brain 2013, 136: 2799-2815.

8. Lai MC, Lombardo MV, Ruigrok AN, Chakrabarti B, Wheelwright SJ, Auyeung B, et al. Cognition in males and females with autism: similarities and differences. PLoS One 2012, 7: e47198.

9. Bölte S, Duketis E, Poustka F, Holtmann M. Sex differences in cognitive domains and their clinical correlates in higher-functioning autism spectrum disorders. Autism 2011, 15: 497-511.

10. Hattier MA, Matson JL, Tureck K, Horovitz M. The effects of gender and age on repetitive and/or restricted behaviors and interests in adults with autism spectrum disorders and intellectual disability. Res Dev Disabil 2011, 32: 2346-2351.

11. Banach R, Thompson A, Szatmari P, Goldberg J, Tuff L, Zwaigenbaum L, et al. Brief report: relationship between nonverbal IQ and gender in autism. J Autism Dev Disord 2009, 39: 188-193.

12. Carter AS, Black DO, Tewani S, Connolly CE, Kadlec MB, Tager-Flusberg H. Sex differences in toddlers with autism spectrum disorders. J Autism Dev Disord 2007, 37: 86-97.

13. Frazier TW, Georgiades S, Bishop SL, Hardan AY. Behavioral and cognitive characteristics of females and males with autism in the simons simplex collection. J Am Acad Child Adolesc Psychiatry $2014,53: 329-340$.
14. Hiller RM, Young RL, Weber N. Sex differences in autism spectrum disorder based on DSM-5 criteria: evidence from clinician and teacher reporting. J Abnorm Child Psychol 2014, 42: 1381-1393.

15. Reinhardt VP, Wetherby AM, Schatschneider C, Lord C. Examination of sex differences in a large sample of young children with autism spectrum disorder and typical development. J Autism Dev Disord 2015, 45:697-706.

16. Goin-Kochel RP, Abbacchi A, Constantino JN. Lack of evidence for increase genetic loading for autism among families of affected females: a replication from family history data in two large samples. Autism, 2007; 11: 279-286.

17. Koenig K, Tsatsanis KD. Pervasive developmental disorders in girls. In Bell DJ, Foster SL, Mash EJ (Eds.), Handbook of behavioral and emotional problems in girls. New York, NY, US: Kluwer Academic/Plenum Publishers, 2005, 211-237.

18. American Psychiatric Association. Diagnostic and Statistical Manual of Mental Disorders, revised (4th ed.). Washington, DC: American Psychiatric Association, 2000.

19. Rutter M, Le Couteur A, Lord C. Autism Diagnostic InterviewRevised Manual. Los Angeles: Western Psychological Services, 2003.

20. Lord C, Rutter M, DiLavore PC, Risi S. Autism Diagnostic Observation Schedule: ADOS manual. Los Angeles, CA: Western Psychological Services, 2002.

21. Holtmann M, Boelte S, Poustka F. Autism spectrum disorders: sex differences in autistic behaviour domains and coexisting psychopathology. Dev Med Child Neurol 2007, 49: 361-366.

22. Howe YJ, O'Rourke JA, Yatchmink Y, Viscidi EW, Jones RN, Morrow EM. Female autism phenotypes investigated at different levels of language and developmental abilities. J Autism Dev Disord 2015, 45: 3537-3549.

23. Bhasin TK, Schendel D. Sociodemographic risk factors for autism in a US metropolitan area. J Autism Dev Disord 2007, 37: 667-677.

24. Lai MC, Lombardo MV, Auyeung B, Chakrabarti B, BaronCohen S. Sex/gender differences and autism: setting the scene for future research. J Am Acad Child Adolesc Psychiatry 2015, 54: $11-24$.

25. Halladay AK, Bishop S, Constantino JN, Daniels AM, Koenig K, Palmer K, et al. Sex and gender differences in autism spectrum disorder: summarizing evidence gaps and identifying emerging areas of priority. Mol Autism 2015, 13: 6-36.

26. Wilson CE, Murphy CM, McAlonan G, Robertson DM, Spain D, Hayward $\mathrm{H}$, et al. Does sex influence the diagnostic evaluation of autism spectrum disorder in adults? Autism 2016, 20: 808-819.

27. Szatmari P, Liu XQ, Goldberg J, Zwaigenbaum L, Paterson AD, Woodbury-Smith M, et al. Sex differences in repetitive stereotyped behaviors in autism: implications for genetic liability. Am J Med Genet B Neuropsychiatr Genet 2012, 159B: 5-12.

28. Tsai L, Stewart MA, August G. Implication of sex differences in the familial transmission of infantile autism. J Autism Dev Disord 1981, 11: 165-173.

29. Shattuck PT, Durkin M, Maenner M, Newschaffer C, Mandell DS, Wiggins L, et al. Timing of identification among children with an autism spectrum disorder: findings from a populationbased surveillance study. J Am Acad Child Adolesc psychiatry 2009, 48: 474-483. 